
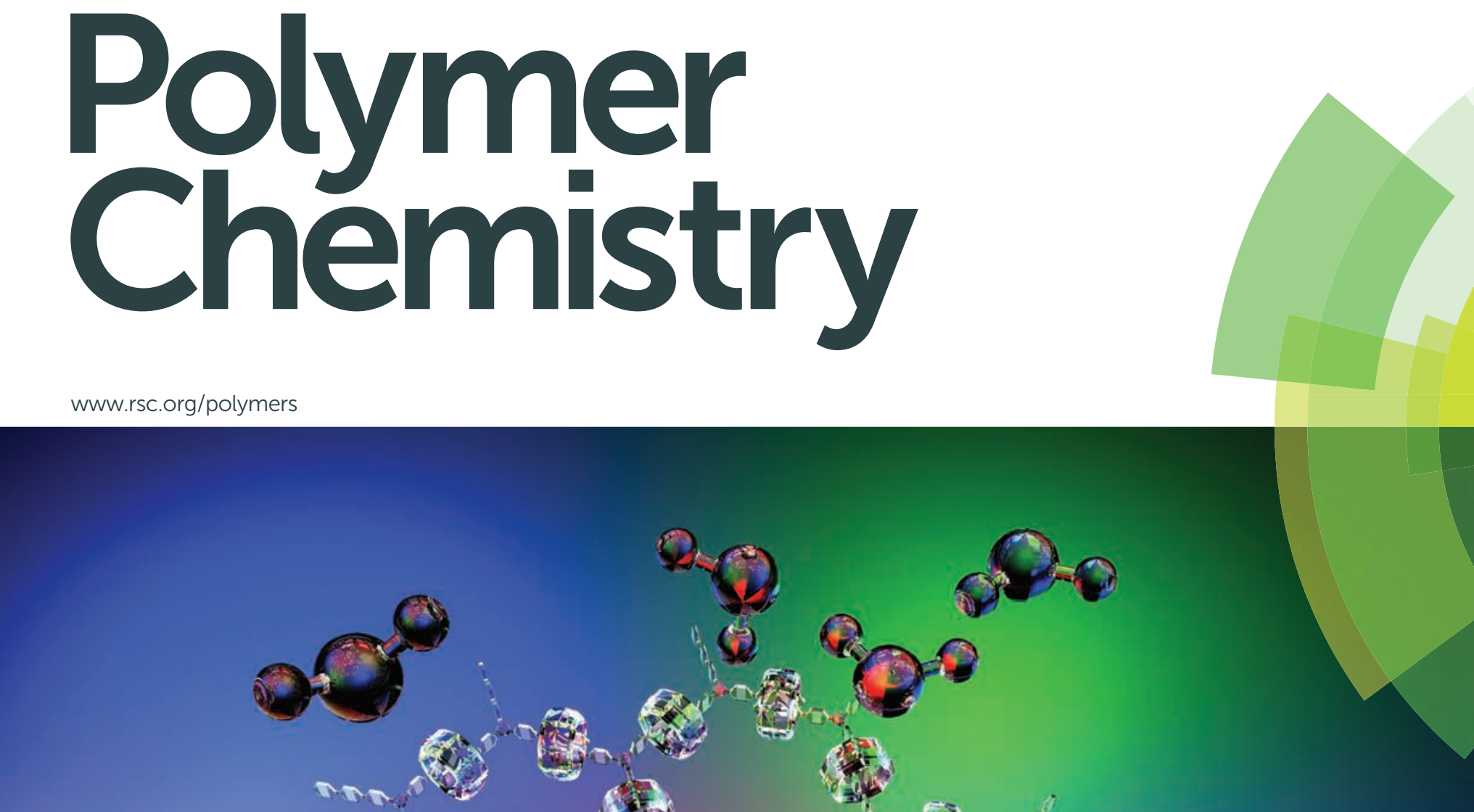

at

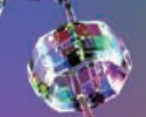

D. $=8 \%$<smiles></smiles>

was

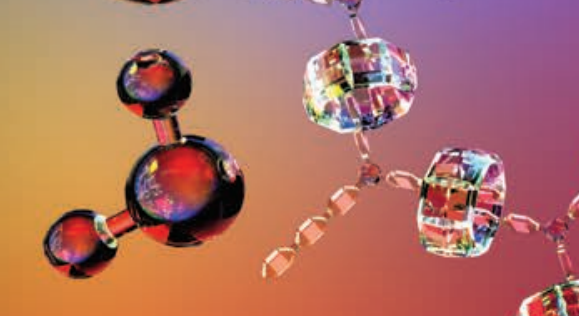

का का

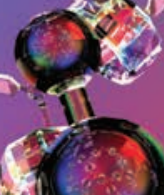

(1)

y $3 y^{5}$
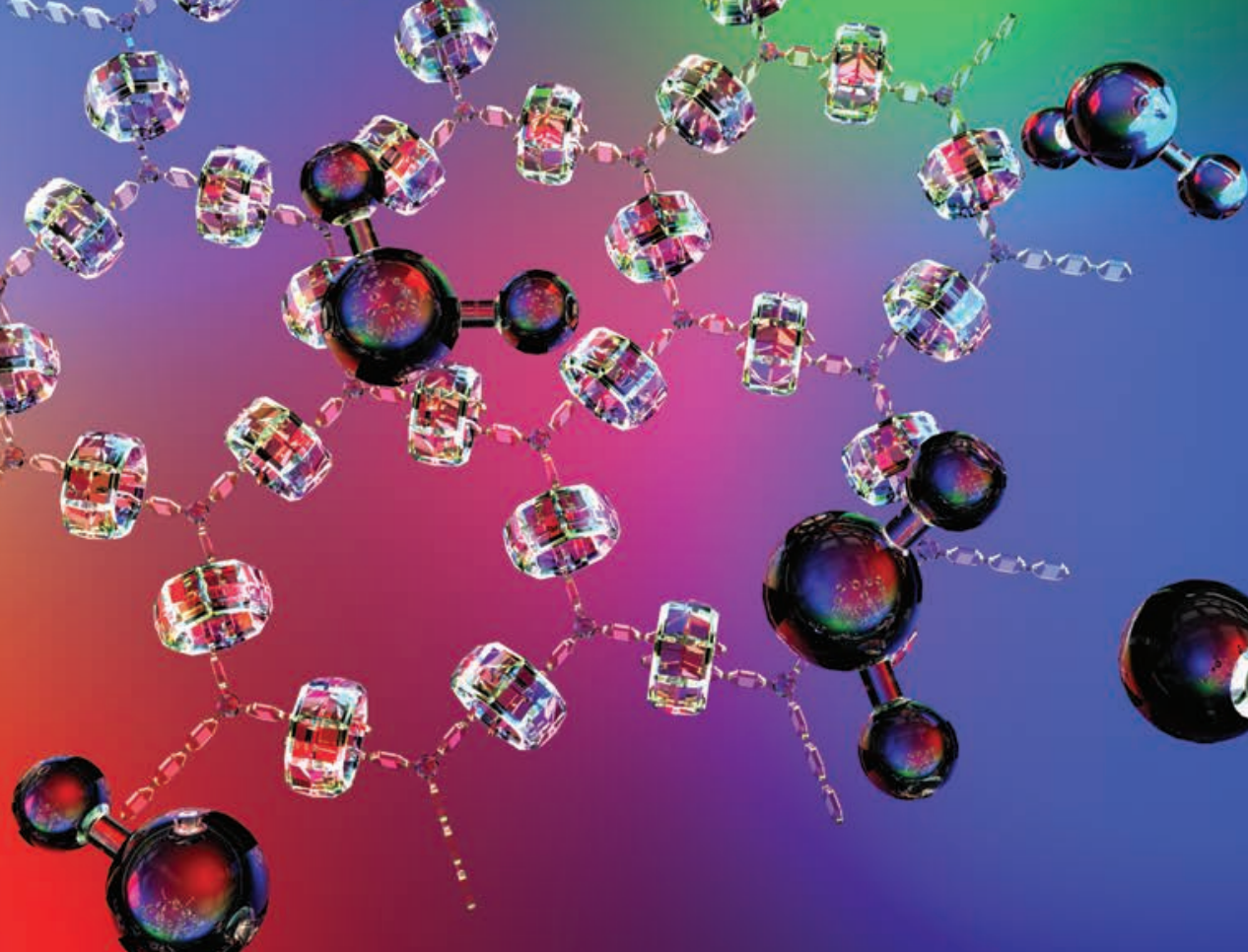

24.

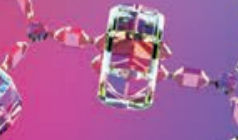




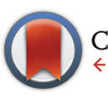

CrossMark \&click for updates

Cite this: Polym. Chem., 2015, 6, 3018

Received 18th January 2015,

Accepted 18th February 2015

DOI: $10.1039 /$ c5py00072f

www.rsc.org/polymers

\title{
Highly thermally stable hydrogels derived from monolayered two-dimensional supramolecular polymers $\uparrow$
}

\author{
Tian-You Zhou, ${ }^{a}$ Qiao-Yan Qi, ${ }^{a}$ Qiao-Ling Zhao, ${ }^{a}$ Jie Fu, ${ }^{a}$ Yi Liu, ${ }^{b}$ Zhi Ma ${ }^{a}$ and \\ Xin Zhao*a
}

\begin{abstract}
It has been predicted that the properties of materials are dramatically influenced if their structures are confined to two-dimensional (2D) space. A representative example is graphene. However, for synthetic 2D materials, such influences have rarely been demonstrated. In this work, a rare example of how a 2D monolayer structure can impact the properties of bulk materials has been demonstrated by the construction of 2D supramolecular polymers (SPS) and their utilization in the fabrication of hydrogels. Maintaining the intrinsic 2D structures, the as-prepared hydrogels exhibited exceptional thermal stabilities $\left(>180{ }^{\circ} \mathrm{C}\right)$, as revealed by an inversion test and a variable-temperature rheological study. The microstructures and morphologies of the 2D SPs have been extensively characterized by NMR spectroscopy, dynamic light scattering, small-angel $\mathrm{X}$-ray scattering, transmission electron microscopy and atomic force microscopy. Furthermore, molecular dynamic simulations were also performed to shed light on the formation mechanism of the hydrogels.
\end{abstract}

\section{Introduction}

The recent boom in research interest on graphene ${ }^{1}$ has spurred great research interest on two dimensional (2D) synthetic materials due to the specific atom arrangement, large surface area and extremely high aspect ratio of 2D structures. ${ }^{2}$ Due to the substantial synthetic challenges, much effort has been devoted towards the controlled synthesis of isolated, layered 2D structures, broadly known as 2D polymers. Several $2 \mathrm{D}$ polymers have been constructed via chemical synthesis ${ }^{3}$ or self-assembly ${ }^{4}$ over the past two years, some of which possess impressive atomic structural precision within individual layers. Despite these great synthetic advances, the emergent material properties derived from the unique 2D structures of such polymers still remain to be demonstrated.

Hydrogels, a family of jelly-like soft materials fabricated from the gelation of water by specific molecules, have been extensively studied in the past few decades because of their

\footnotetext{
${ }^{a}$ Key Laboratory of Synthetic and Self-Assembly Chemistry for Organic Functional Molecules, Shanghai Institute of Organic Chemistry, Chinese Academy of Sciences, 345 Lingling Road, Shanghai, 200032, China.E-mail:xzhao@mail.sioc.ac.cn ${ }^{b}$ The Molecular Foundry, Lawrence Berkeley National Laboratory, One Cyclotron Road, MS 67R6110, Berkeley, CA 94720, USA

$\dagger$ Electronic supplementary information (ESI) available: Synthesis and characterizations of compounds, ${ }^{1} \mathrm{H}$ NMR $2 \mathrm{D}$ NOESY spectra, variable-temperature ${ }^{1} \mathrm{H}$ NMR spectra, SEM images, POM images, pictures of the hydrogels, additional rheological experiments, ${ }^{1} \mathrm{H}$ NMR titration spectra and TEM images. See DOI: 10.1039/c5py00072f
}

widespread applications in biomaterials, ${ }^{5}$ chemosensors, ${ }^{6}$ and separation technology. ${ }^{7}$ A general mechanism for the formation of hydrogels is the immobilization of water molecules in three-dimensional (3D) networks, which are created by the entanglement of linear polymers or nanofibers self-assembled from small molecules. The thermal stabilities of hydrogels are usually quite low, especially for hydrogels fabricated from the self-assembly of small molecules. This prevents them from being used at elevated temperatures. ${ }^{8}$

In this article, we demonstrate a rare example of how a $2 \mathrm{D}$ monolayer structure can impact the properties of bulk materials by the construction of $2 \mathrm{D}$ supramolecular polymers (SPs) and their utilization in the formation of hydrogels with exceptional thermal stabilities (Scheme 1). These hydrogels with intrinsic 2D periodical structures exhibit extremely high thermal stabilities. The gel phase and elasticity are maintained even at $180{ }^{\circ} \mathrm{C}$, significantly above the boiling point of water, demonstrating that the thermal stability of a hydrogel could be significantly enhanced by taking advantage of the unique features of a 2D structure. The building blocks for the construction of 2D SPs were designed by incorporating three phenylpyridinium (PP) units into the para-positions of a triphenylamine skeleton (1 and 2, Scheme 1). The dimerization of PP units can be considerably enhanced by the encapsulation of two PP units in the cavity of a $\mathrm{CB}[8]$ molecule, ${ }^{9}$ an approach employing the potent cucurbit[8]uril ( $\mathrm{CB}[8])$-based host-guest chemistry. ${ }^{10}$ As revealed by our previous work, ${ }^{9}$ the two PP units should adopt a head-to-tail arrangement in the cavity of 


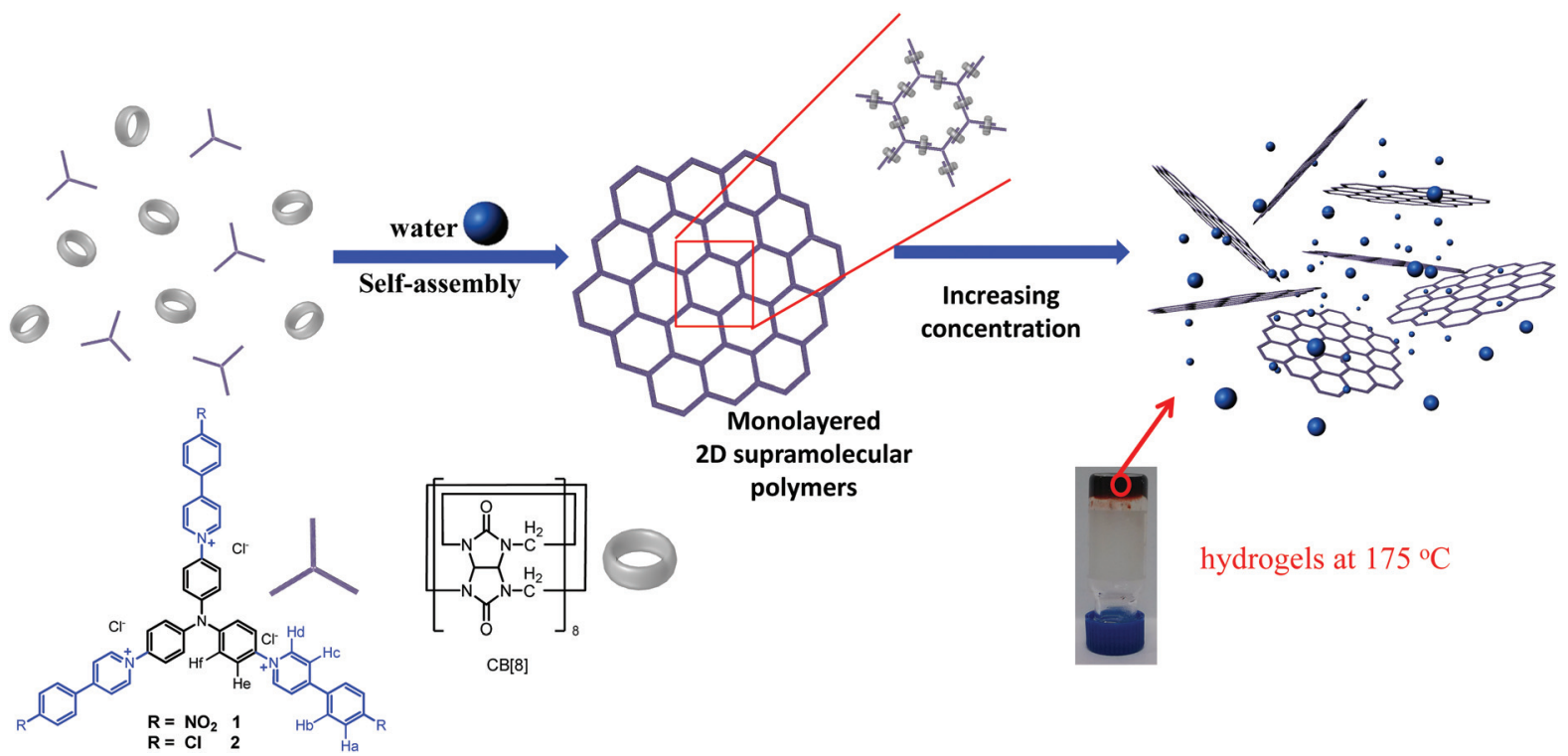

Scheme 1 Structures of building blocks 1, 2 and CB[8], and cartoon representations of the formation of 2D SPs and hydrogels.

$\mathrm{CB}[8]$. This advantage removes the requirement to introduce steric groups into the skeleton of the monomer, which was necessary for the first example of a 2D SP reported by us recently. ${ }^{4 a}$ In that system dimerization of the whole monomer was observed as a result of the head-to-head arrangement of the 4,4'-bipyridin-1-ium (BP) units in the cavity of $\mathrm{CB}[8]$ when steric groups were not introduced. DFT calculations revealed that these triphenylamine-based building blocks adopted a $C_{3}$ symmetric conformation with a coplanar arrangement of the three $N$-aryl bonds (Fig. S1, ESI $\dagger$ ), which could facilitate the formation of extended 2D networks with hexagonal pores.

\section{Results and discussion}

Characterization of the assembled structures in solution phase

The binding between building block 1 and $\mathrm{CB}[8]$ was first investigated by ${ }^{1} \mathrm{H}$ NMR titration experiments (Fig. 1). Follow- ing the addition of $\mathrm{CB}[8]$ into a solution of $\mathbf{1}$ in $\mathrm{D}_{2} \mathrm{O}$, the intensities of the protons $\left(\mathrm{H}_{\mathrm{a}}-\mathrm{H}_{\mathrm{d}}\right)$ of the PP units decreased while the signals corresponding to the protons $\left(\mathrm{H}_{\mathrm{e}}\right.$ and $\left.\mathrm{H}_{\mathrm{f}}\right)$ of the triphenyl amine segment remained almost unchanged. At the same time, a new set of signals grew in the range of 9.1-6.8 ppm. This new set of signals is attributed to the encapsulated PP units in the cavity of $\mathrm{CB}[8]$, for which the rate of interchange between encapsulated and non-encapsulated 1 was slower than the NMR time scale. ${ }^{11}$ The binding stoichiometry between 1 and $\mathrm{CB}[8]$ was revealed to be $2: 3$ by a Job's plot (Fig. S2, ESI $\dagger$ ). This was also reflected by the ${ }^{1} \mathrm{H}$ NMR titration experiments: no further changes in the signals were observed after the ratio of 1 to $\mathrm{CB}[8]$ reached $2: 3$. The dimerization of the PP units in the cavity of $\mathrm{CB}[8]$ was further corroborated by $2 \mathrm{D}{ }^{1} \mathrm{H}$ NMR nuclear Overhauser effect spectroscopy (NOESY). Through-space correlations were observed between $\mathrm{H}_{\mathrm{a}}$ and $\mathrm{H}_{\mathrm{d}}$, and $\mathrm{H}_{\mathrm{b}}$ and $\mathrm{H}_{\mathrm{d}}$ (Fig. S3, ESI $\dagger$ ), clearly indicating a head-to-tail arrangement of two PP units in the cavity of one

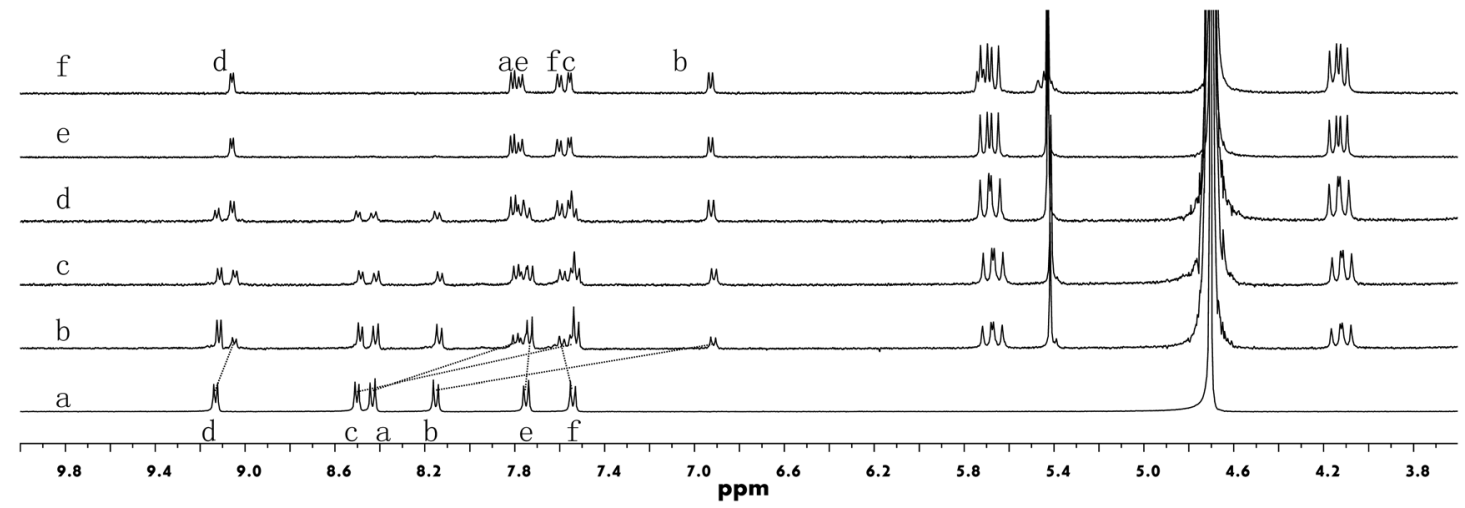

Fig. $1{ }^{1} \mathrm{H}$ NMR spectra $(500 \mathrm{MHz})$ of (a) 1 (0.5 mM), (b) $1+\mathrm{CB}[8](0.3$ equiv.), (c) $1+\mathrm{CB}[8](0.75$ equiv.), (d) $1+\mathrm{CB}[8]$ (1.1 equiv.), (e) $1+\mathrm{CB}[8]$ (1.5 equiv.), and ( $f) 1+C B[8]$ (1.8 equiv.) in $\mathrm{D}_{2} \mathrm{O}$ at $25^{\circ} \mathrm{C}$. 
$\mathrm{CB}[8]$ molecule. Driven by such host-guest interactions, the formation of extended honeycomb-like 2D networks could be expected as a result of the precise direction control offered by the rigid skeleton of the building blocks. Compound 2 exhibited similar complexation behavior as compound $\mathbf{1}$ when mixed with $\mathrm{CB}[8]$ (Fig. S4-S6, ESI $\dagger$ ).

The formation of polymeric structures in solution was proven by dynamic light scattering (DLS). With the increase of concentration, the hydrodynamic diameter $\left(D_{\mathrm{h}}\right)$ of the mixture of 1 and $\mathrm{CB}[8]$ (2:3) in water increased sharply within the low concentration range (lower than $0.05 \mathrm{mM}$ ) and then became much more smooth and finally reached a plateau value around $1100 \mathrm{~nm}$ at higher concentrations (Fig. S7, ESI $\dagger$ ). The mixture of 2 and $\mathrm{CB}[8]$ also gave a similar trend (Fig. S8, ESI $\dagger$ ). These results suggest that supramolecular polymers formed even at very low concentrations and reached equilibrium at high concentrations. This is a typical feature of self-assembled systems which are under thermodynamic control.

The molecular weights of the supramolecular polymers were estimated by static light scattering (SLS) experiments. It was also found that the molecular weights increased monotonically with the concentrations of the stoichiometric $(2: 3)$ mixtures of $[\mathbf{1}+\mathrm{CB}[8]]$ and $[2+\mathrm{CB}[8]]$ (Fig. S9, ESI $\dagger$ ). At the highest concentration recorded $(0.45 \mathrm{mM}$ for 1 and 2$)$, the molecular weights were estimated to be $1.36 \times 10^{6}$ and $8.5 \times 10^{5} \mathrm{~g} \mathrm{~mol}^{-1}$, corresponding to degrees of polymerization of 462 and 292 for the 2D polymers fabricated from 1 and 2, respectively.

\section{The formation of highly thermally stable hydrogels}

When the concentrations of the self-assembled systems were further increased, formation of hydrogels was observed (Fig. S10-11, ESI $\dagger$ ). The critical gelation concentrations of the hydrogels were estimated to be $c a .2 .0 \mathrm{mM}$ (6.5 wt\%) for 1-CB[8] and $2.5 \mathrm{mM}(7.8 \mathrm{wt} \%)$ for $2-\mathrm{CB}[8]$, respectively. Notably, these hydrogels exhibited extremely high thermal stabilities. The gel state could still be maintained even at $175{ }^{\circ} \mathrm{C}$ for the hydrogel fabricated from 1 and $\mathrm{CB}[8]$ under an ambient atmosphere in a sealed tube. Furthermore, no hydrogel collapse was observed after the as-prepared hydrogel was sonicated for 10 minutes. The hydrogel fabricated from 2 and $\mathrm{CB}[8]$ also exhibited a comparable high thermal stability. The high thermal stabilities of the supramolecular structures in solution were also confirmed by variable-temperature ${ }^{1} \mathrm{H}$ NMR studies. When the temperature was increased from 25 to $75{ }^{\circ} \mathrm{C}$, no observable changes were detected for the chemical shifts and the shape of the signals in the SP spectra, suggesting the 2D polymeric structures were maintained over this temperature range (Fig. S12-13, ESI $\dagger$ ). Although ${ }^{1} \mathrm{H}$ NMR experiments at higher temperatures were not conducted on account of pressure buildup in the NMR tube, the SPs are expected to remain stable in solution at temperatures well above $75{ }^{\circ} \mathrm{C}$. In addition, the apparent binding constants $\left(K_{\mathrm{a}}\right)$ were determined by fitting the data obtained from UV-vis titration experiments at 25 and $75{ }^{\circ} \mathrm{C}$. Both of the SPs exhibited high binding strengths. At $25{ }^{\circ} \mathrm{C}, 1-\mathrm{CB}[8]$ had a $K_{\mathrm{a}}$ value of $1.68( \pm 0.18) \times$ $10^{12} \mathrm{M}^{-2}$ and for $2-\mathrm{CB}[8]$ the value was $6.75( \pm 0.55) \times 10^{12} \mathrm{M}^{-2}$.
As the temperature increased to $75^{\circ} \mathrm{C}$, the $K_{\mathrm{a}}$ value for $1-\mathrm{CB}[8]$ remained almost unchanged $\left(1.37( \pm 0.05) \times 10^{12} \mathrm{M}^{-2}\right)$, while the value for $2-\mathrm{CB}[8]$ slightly decreased to $6.08( \pm 0.85) \times$ $10^{11} \mathrm{M}^{-2}$, indicating again the high thermal stabilities of the SPs (Fig. S14, ESI $\dagger$ ).

In order to get some insights to the properties of the hydrogels, the rheological properties of the hydrogels were first investigated at 25 and $80{ }^{\circ} \mathrm{C}$ under an ambient atmosphere. ${ }^{12}$ At the two temperatures, both hydrogels exhibited higher storage modulus $\left(G^{\prime}\right)$ values than loss modulus $\left(G^{\prime \prime}\right)$ values over the whole scanning frequency range recorded (Fig. S15, ESI $\dagger$ ). This result clearly indicates that these hydrogels exhibited typical elastic properties and the elasticity was maintained at elevated temperatures. Temperature-dependent rheological experiments were further performed to get a deeper insight into the thermal stabilities of the hydrogels. These experiments were carried out in a sealed nitrogen atmosphere under 50 bar pressure to avoid the evaporation of water. The following observations confirmed the high thermal stabilities of both hydrogels: (i) the storage modulus values of the hydrogels were always higher than their loss modulus values over the whole temperature range recorded $\left(30-180{ }^{\circ} \mathrm{C}\right.$ ); (ii) the values of both the storage modulus and loss modulus of the hydrogels remained nearly constant over the whole temperature range (Fig. 2).

The morphologies of the xerogels after water was evaporated were examined by scanning electron microscopy (SEM). Layered flakes were observed, consistent with the postulation that the hydrogels were derived from 2D sheets (Fig. S16, ESI $\dagger$ ). A polarized optical microscopy (POM) study on the xerogels revealed birefringence textures corresponding to crystalline features (Fig. S17, ESI $\dagger$ ), suggestive of well-ordered internal microstructures in these hydrogels. The hydrogel was regenerated when water was introduced into the xerogel fabricated from 1 and $\mathrm{CB}[8]$, indicating re-hydration of the dehydrated 2D SP structures.

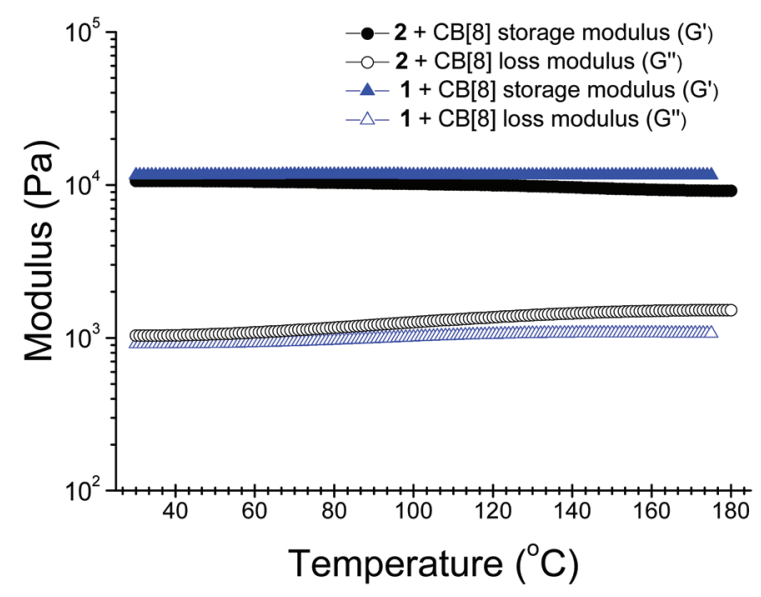

Fig. 2 Temperature-dependent storage modulus $\left(G^{\prime}\right)$ and loss modulus $\left(G^{\prime \prime}\right)$ for the hydrogels fabricated from $\mathrm{CB}[8]$ and 1 or 2 (50 bar, $1 \mathrm{~Hz}$; $\left.2{ }^{\circ} \mathrm{C} \mathrm{min}^{-1}\right)$. The concentrations used were $16.4 \mathrm{wt} \%$ for $1-\mathrm{CB}[8]$ and 15.6 wt\% for $2-\mathrm{CB}[8]$. The molar ratio for $\mathrm{CB}[8]$ to 1 or 2 was $2: 3$. 


\section{Evidence for the formation of single-layer 2D sheets}

The extremely high thermal stabilities of these hydrogels are attributed to their distinctive formation mechanism, which is proposed to be driven by the interactions between water molecules and the extraordinarily large surface area of the $2 \mathrm{D}$ polymeric structures. The mechanism is markedly different from the conventional hydrogels reported previously, which were usually generated through 3D entangling of linear fiber-like structures. In order to investigate the formation of $2 \mathrm{D}$ supramolecular polymer layers, a variety of techniques have been used to characterize the structures of the materials formed through the self-assembly of $\mathrm{CB}[8]$ and $\mathbf{1}$ or 2 in water. The morphologies of the self-assembled structures were first characterized by transmission electron microscopy (TEM). As can be seen in Fig. 3a, sheet-like structures can be observed for the sample prepared from $[\mathbf{1}+\mathrm{CB}[8](2: 3)]$. The contrast between the sheets and the TEM substrate (copper grid-supported carbon film) was very low, consistent with the ultra thin thickness of single layer sheets. Larger area sheets with lateral
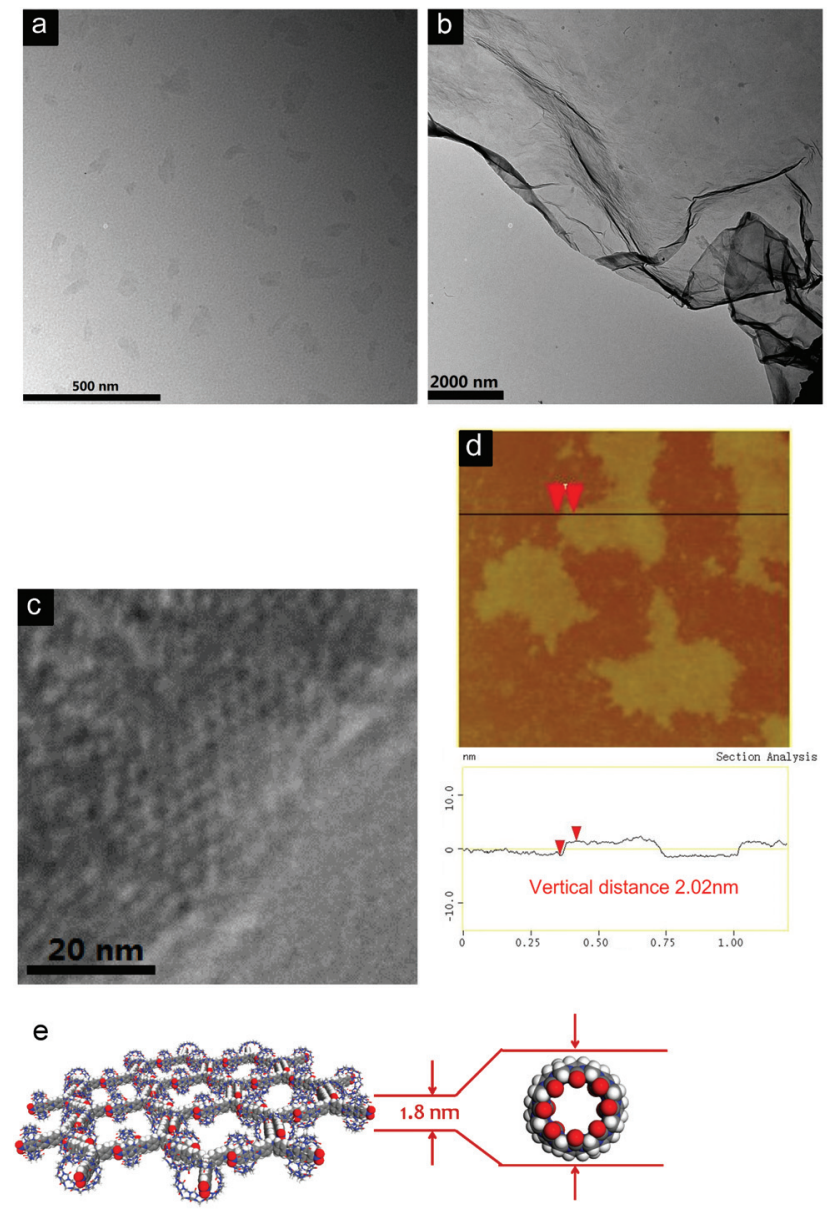

Fig. 3 TEM images of samples (a) $1(0.05 \mathrm{mM})$ and $C B[8](0.075 \mathrm{mM})$ and (b) 1 (0.25 mM) and $C B[8](0.375 \mathrm{mM})$. (c) HR-TEM image of the sheet, indicating its honeycomb-like microstructure. (d) Tapping-mode AFM image and cross-section analysis of the sample of [1 + CB[8] (2:3)]. (e) Theoretical thickness of the monolayered 2D SPs. The concentration was $0.05 \mathrm{mM}$ for 1 . sizes up to several micrometers were also observed at higher concentrations (Fig. 3b). Similar TEM results were also obtained for the sample prepared from [2+CB[8] (2:3)] (Fig. S18, ESI $\dagger$ ). Most notably, honeycomb units with a pore size of around $3.6 \mathrm{~nm}$ could be observed by high resolution (HR)-TEM (Fig. 3c). This gives direct evidence for the formation of the proposed 2D network. Since the thicknesses of the sheets could not be estimated from TEM, atomic force microscopy (AFM) was employed to characterize the sheet-like assemblies. Flat and uniform sheets were observed by AFM measurements, with thicknesses of 2.02 and $2.21 \mathrm{~nm}$ for the SPs fabricated from 1 and 2 with $\mathrm{CB}[8]$, respectively (Fig. 3d and S19, ESI $\dagger$ ). These values are very close to the theoretical thicknesses of the expected monolayered 2D sheets determined by the outer diameter of $\mathrm{CB}[8]$ (Fig. 3e). ${ }^{13}$

\section{Evidence for long-range ordered 2D periodicity in the 2D SPs}

A key criterion for a true $2 \mathrm{D}$ polymer is the existence of longrange ordered periodicity in two dimensions. In order to prove that the sheets generated by the self-assembly of $\mathrm{CB}[8]$ and 1 or 2 did hold periodic $2 \mathrm{D}$ polymeric structures, small angle $\mathrm{X}$-ray scattering (SAXS) experiments were carried out. For the sample fabricated from 1 and $\mathrm{CB}[8],{ }^{14}$ a scattering peak corresponding to a $d$ spacing of $3.61 \mathrm{~nm}$ (100) was observed (Fig. 4a). Moreover, a (200) scattering peak was also observed at a $d$ spacing of $1.81 \mathrm{~nm}$, further confirming the existence of a periodic size of $3.61 \mathrm{~nm}$. In the case of the sample prepared from 2 and $\mathrm{CB}[8]$, scattering peaks corresponding to (100) and (200) were observed at 3.49 and $1.73 \mathrm{~nm}$, respectively (Fig. 4c). Semiempirical calculations at PM3 level revealed that the theoretical pore diameter of the expected honeycomb structure is $3.60 \mathrm{~nm}$ for both of the SPs fabricated from the co-assembly of $\mathrm{CB}[8]$ with 1 or 2 . The experimentally obtained values agree well with the theoretical ones, corroborating the formation of
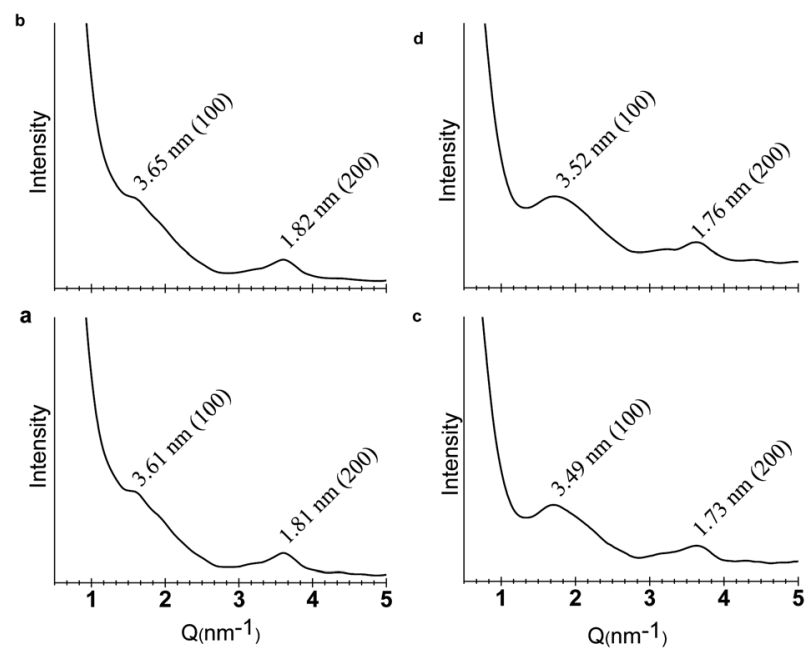

Fig. 4 SAXS patterns of the sample prepared from a hydrogel of 1 and $\mathrm{CB}[8](13.0 \mathrm{wt} \%)$ in water $(\mathrm{pH}=7)$ at (a) $25^{\circ} \mathrm{C}$ and (b) $85^{\circ} \mathrm{C}$. SAXS patterns of the sample prepared from a hydrogel of 2 and $\mathrm{CB}$ [8] (9.36 wt\%) in water $(\mathrm{pH}=7)$ at (c) $25^{\circ} \mathrm{C}$ and (d) $85^{\circ} \mathrm{C}$. 


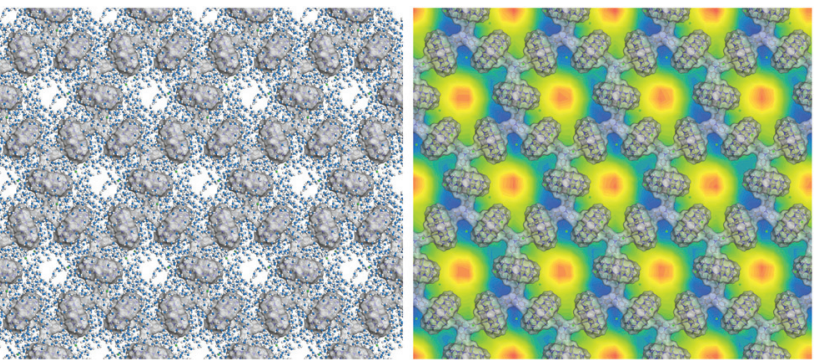

Fig. 5 Left: a snapshot of the simulated hydrogel formed from 1 and $\mathrm{CB}[8]$. The skeleton is illustrated by a Connolly surface for clarity. The oxygen atoms of $\mathrm{H}_{2} \mathrm{O}$ are represented by the blue-colored particles, the hydrogen atoms are represented by the gray-colored particles and $\mathrm{Cl}^{-}$ ions are represented by the green-colored particles. Right: the statistical slice of the density field of $\mathrm{H}_{2} \mathrm{O}$ to display the water distribution on the 2D structure. The blue color shows the relatively high density of $\mathrm{H}_{2} \mathrm{O}$ and the red color shows the relatively low density of $\mathrm{H}_{2} \mathrm{O}$. This indicates that the water molecules are more distributed near the skeleton of the 2D SP.

the expected 2D networks with well-ordered internal microstructures. These scattering peaks could still be observed when the samples were heated to $85{ }^{\circ} \mathrm{C}$ (Fig. $4 \mathrm{~b}$ and d), suggesting that the 2D networks remained intact at elevated temperatures. This again indicates the high thermal stabilities of these 2D supramolecular polymers.

In order to shed light on the formation mechanism of the hydrogels, molecular dynamic simulations were performed for the hydrogel formed from 1 and $\mathrm{CB}[8]$ (Fig. 5, see ESI for more details $\dagger)$. A snapshot of a $(4 \times 4)$ segment of the $2 \mathrm{D}$ layer revealed that water molecules were mainly distributed near the skeleton of the honeycomb structure. In contrast, the pore centers had the lowest distribution density of water molecules. This result suggests that the $2 \mathrm{D}$ supramolecular polymers have a high affinity for water molecules, which may be ascribed to the formation of hydrogen bonds between the $\mathrm{O}$ and $\mathrm{N}$ atoms of $\mathrm{CB}[8]$ and the $\mathrm{NO}_{2}$ groups of the $\mathrm{PP}$ units (for building block 1). Through these hydrogen-bonding interactions, a huge number of water molecules could be localized on the surfaces of the monolayered sheets, which further extended to produce hydrogels. In this context, the high thermal stability of the hydrogel could be attributed to the extraordinarily large surface areas of the $2 \mathrm{D}$ structures, which provide a maximum number of interaction sites for the formation of hydrogen bonds. Compared to 2- $\mathrm{CB}[8], 1-\mathrm{CB}[8]$ exhibited a lower critical gelation concentration and higher molecular weights and storage modulus. This could be attributed to the additional hydrogenbonding sites provided by the nitro group of compound 1 .

\section{Conclusions}

In conclusion, the significant impact of a unique 2D structure on the performance of soft materials has been demonstrated. Different from traditional hydrogels, which are usually formed by the 3D entanglement of flexible linear structures, the hydrogels reported here were generated from monolayered 2D supra- molecular polymers without any flexible side chains. Thanks to the extraordinarily large surface areas of the 2D structures, a maximum number of interaction sites is provided to immobilize water molecules on the surfaces and thus the thermal stabilities of the hydrogels are enhanced significantly. Currently the research on synthetic $2 \mathrm{D}$ polymers is still at a very early stage. Much attention has been paid to the construction and characterization of $2 \mathrm{D}$ structures, while their properties and applications are awaiting further exploration. The highly thermostable hydrogels demonstrated in this work reveal that the unique features of $2 \mathrm{D}$ structures could be essential for the fabrication of unconventional functional materials. As this work takes advantage of only one feature of 2D structures, i.e. the large surface area, we believe that the other features of this type of structure will also endow 2D polymer-based materials with unique properties and functions. For example, the longrange ordered periodicity in $2 \mathrm{D}$ space could be exploited for the construction of well-ordered arrays of sensors to achieve ultrahigh sensitivity. This is currently under investigation in our laboratory.

\section{Acknowledgements}

We thank the National Natural Science Foundation of China (nos. 21172249 and 91127007) for financial support. Y.L. acknowledges the support from the Molecular Foundry, Lawrence Berkeley National Laboratory, supported by the Office of Science, Office of Basic Energy Sciences, Scientific User Facilities Division, of the U.S. Department of Energy under Contract no. DE-AC02-05CH11231. We also thank Prof. Zhan-Ting Li and Mr Jia Tian (Fudan University) for their help in preparing the manuscript and Prof. Li-Zhu Wu (Technical Institute of Physics and Chemistry) for her helpful advice.

\section{Notes and references}

1 (a) K. S. Novoselov, A. K. Geim, S. V. Morozov, D. Jiang, Y. Zhang, S. V. Dubonos, I. V. Grigorieva and A. A. Firsov, Science, 2004, 306, 666; (b) K. S. Novoselov, A. K. Geim, S. V. Morozov, D. Jiang, M. I. Katsnelson, I. V. Grigorieva, S. V. Dubonos and A. A. Firsov, Nature, 2005, 438, 197; (c) M. J. Allen, V. C. Tung and R. B. Kaner, Chem. Rev., 2010, 110, 132.

2 (a) J. Sakamoto, J. van Heijst, O. Lukin and A. D. Schlüter, Angew. Chem., Int. Ed., 2009, 48, 1030; (b) R. Mas-Ballesté, C. Gómez-Navarro, J. Gómez-Herrero and F. Zamora, Nanoscale, 2011, 3, 20.

3 (a) T.-Y. Zhou, F. Lin, Z.-T. Li and X. Zhao, Macromolecules, 2013, 46, 7745; (b) P. Kissel, R. Erni, W. B. Schweizer, M. D. Rossell, B. T. King, T. Bauer, S. Gotzinger, A. D. Schlüter and J. Sakamoto, Nat. Chem., 2012, 4, 287; (c) P. Kissel, D. J. Murray, W. J. Wulftange, V. J. Catalano and B. T. King, Nat. Chem., 2014, 6, 774; (d) M. J. Kory, M. Wörle, T. Weber, P. Payamyar, S. W. van de Poll, J. Dshemuchadse, N. Trapp and A. D. Schlüter, Nat. Chem., 
2014, 6, 779; (e) K. Baek, G. Yun, Y. Kim, D. Kim, R. Hota, I. Hwang, D. Xu, Y. H. Ko, G. H. Gu, J. H. Suh, C. G. Park, B. J. Sung and K. Kim, J. Am. Chem. Soc., 2013, 135, 6523.

4 (a) K.-D. Zhang, J. Tian, D. Hanifi, Y. Zhang, A. C.-H. Sue, T.-Y. Zhou, L. Zhang, X. Zhao, Y. Liu and Z.-T. Li, J. Am. Chem. Soc., 2013, 135, 17913; (b) L. Zhang, T.-Y. Zhou, J. Tian, H. Wang, D.-W. Zhang, X. Zhao and Z.-T. Li, Polym. Chem., 2014, 5, 4715; (c) X. Zhang, C.-B. Nie, T.-Y. Zhou, Q.-Y. Qi, J. Fu, X.-Z. Wang, L. Dai, Y. Chen and X. Zhao, Polym. Chem., 2015, 6, 1923.

5 (a) O. P. Oommen, S. Wang, M. Kisiel, M. Sloff, J. Hilborn and O. P. Varghese, Adv. Funct. Mater., 2013, 23, 1273; (b) N. Annabi, K. Tsang, S. M. Mithieux, M. Nikkhah, A. Ameri, A. Khademhosseini and A. S. Weiss, Adv. Funct. Mater., 2013, 23, 4950; (c) Y. Liu and M. B. Chan-Park, Biomaterials, 2009, 30, 196.

6 (a) D. Zhai, B. Liu, Y. Shi, L. Pan, Y. Wang, W. Li, R. Zhang and G. Yu, ACS Nano, 2013, 7, 3540; (b) D. Pussak, D. Ponader, S. Mosca, S. V. Ruiz, L. Hartmann and S. Schmidt, Angew. Chem., Int. Ed., 2013, 52, 6084; (c) S. Bhowmik, B. N. Ghosh, V. Marjomaki and K. Rissanen, J. Am. Chem. Soc., 2014, 136, 5543.

7 (a) Y. Liu, S. Yu, H. Wu, Y. Li, S. Wang, Z. Tian and Z. Jiang, J. Membr. Sci., 2014, 469, 198; (b) F. Lu, Y. Chen, N. Liu, Y. Cao, L. Xu, Y. Wei and L. Feng, RSC Adv., 2014, 4, 32544.

8 (a) M. Guo, L. Pitet, H. Wyss, M. Vos, P. Y. W. Dankers and E. W. Meijer, J. Am. Chem. Soc., 2014, 136, 6969; (b) Z. Lv, L. Chang, X. Long, J. Liu, Y. Xiang, J. Liu, J. Liu, H. Deng, L. Deng and A. Dong, Carbohydr. Polym., 2014, 108, 26; (c) F. Lv, L. Mao and T. Liu, Mater. Sci. Eng., C, 2014, 43, 221; (d) G. Azevedo, B. Domingues, H. Abreu, I. SousaPinto, G. Feio and L. Hilliou, Carbohydr. Polym., 2014, 108, 140.

9 Y. Zhang, T.-Y. Zhou, K.-D. Zhang, J.-L. Dai, Y.-Y. Zhu and X. Zhao, Chem. - Asian. J., 2014, 9, 1530.

10 (a) C. Yang, T. Mori, Y. Origane, Y. H. Ko, N. Selvapalam, K. Kim and Y. Inoue, J. Am. Chem. Soc., 2008, 130, 8574; (b) Y. H. Ko, Y. Kim, H. Kim and K. Kim, Chem. - Asian. J.,
2011, 6, 652; (c) Z.-J. Ding, H.-Y. Zhang, L.-H. Wang, F. Ding and Y. Liu, Org. Lett., 2011, 13, 856; (d) Q. Wang, Y. Chen and Y. Liu, Polym. Chem., 2013, 4, 4192; (e) W. S. Jeon, H. J. Kim, C. Lee and K. Kim, Chem. Commun., 2002, 1828; (f) A. Y. Ziganshina, Y. H. Ko, W. S. Jeon and K. Kim, Chem. Commun., 2004, 806; $(g)$ Y. Lan, Y. Wu, A. Karas and O. A. Scherman, Angew. Chem., Int. Ed., 2014, 53, 2166; (h) Z. Huang, L. Yang, Y. Liu, Z. Wang, O. A. Scherman and X. Zhang, Angew. Chem., Int. Ed., 2014, 53, 5351; (i) J. R. McKee, E. A. Appel, J. Seitsonen, E. Kontturi, O. A. Scherman and O. Ikkala, Adv. Funct. Mater., 2014, 24, 2706; $(j)$ F. Biedermann, I. Ross and O. A. Scherman, Polym. Chem., 2014, 5, 5375; (k) J. del Barrio, P. N. Horton, D. Lairez, G. O. Lloyd, C. Toprakcioglu and O. A. Scherman, J. Am. Chem. Soc., 2013, 135, 11760; (l) F. Biedermann, M. Vendruscolo, O. A. Scherman, A. De Simone and W. M. Nau, J. Am. Chem. Soc., 2013, 135, 14879; (m) H. Qian, D.-S. Guo and Y. Liu, Chem. - Eur. J., 2012, 18, 5087; (n) C. Yang, C. Ke, W. T. Liang, G. Fukuhara, T. Mori, Y. Liu and Y. Inoue, J. Am. Chem. Soc., 2011, 133, 13786; (o) H. Yang, B. Yuan, X. Zhang and O. A. Scherman, Acc. Chem. Res., 2014, 47, 2106; ( $p$ ) H. Yang, Z. Ma, Z. Wang and X. Zhang, Polym. Chem., 2014, 5, 1471; (q) F. Lin, T.-G. Zhan, T.-Y. Zhou, K.-D. Zhang, G.-Y. Li, J. Wu and X. Zhao, Chem. Commun., 2014, 50, 7982.

11 Z.-J. Zhang, H.-Y. Zhang, L. Chen and Y. Liu, J. Org. Chem., 2011, 76, 8270.

12 (a) G. Yu, X. Yan, C. Han and F. Huang, Chem. Soc. Rev., 2013, 42, 6697; (b) X. Yan, D. Xu, X. Chi, J. Chen, S. Dong, X. Ding, Y. Yu and F. Huang, Adv. Mater., 2012, 24, 362; (c) J. W. Steed, Chem. Soc. Rev., 2010, 39, 3686.

13 K. Kim, N. Selvapalam, Y. H. Ko, K. M. Park, D. Kim and J. Kim, Chem. Soc. Rev., 2007, 36, 267.

14 In order to inject the samples into the sample tube of SAXS, partially gelated samples were prepared for SAXS experiment by dispersing the as-prepared hydrogels in water. 